\title{
Upconversion 3D Printed Composite with Multifunctional Applications for Tissue Engineering and Photodynamic Therapy
}

\author{
Karina Nigoghossian, ${ }^{(} *, \#, a$ Sybele Saska, ${ }^{\#, a}$ Livia M. Christovam, ${ }^{a}$ Fernanda Coelho, ${ }^{b}$ \\ Cesar Augusto G. Beatrice, ${ }^{c}$ Alessandra A. Lucas, ${ }^{c}$ Paulo I. Neto, ${ }^{d}$ \\ Jorge Vicente L. da Silva, ${ }^{d}$ Agnieszka Tercjak, ${ }^{\oplus e}$ Maurício S. Baptista, ${ }^{f}$ \\ Luiz Henrique Catalani, ${ }^{f}$ Raquel M. Scarel-Caminaga, ${ }^{b}$ Ticiana S. O. Capote ${ }^{b}$ \\ and Sidney José L. Ribeiro*,a \\ anstituto de Química, Universidade Estadual Paulista (Unesp), 14800-900 Araraquara-SP, Brazil \\ ${ }^{b}$ Faculdade de Odontologia, Universidade Estadual Paulista (Unesp), 14801-903 Araraquara-SP, Brazil \\ ${ }^{c}$ Departamento de Engenharia de Materiais, Universidade Federal de São Carlos (UFSCar), \\ 13565-905 São Carlos-SP, Brazil \\ ${ }^{d}$ Núcleo de Tecnologias Tridimensionais, Centro de Tecnologia da Informação Renato Archer (CTI), \\ 13069-901 Campinas-SP, Brazil \\ ${ }^{e}$ Group "Materials + Technologies" (GMT), Department of Chemical and Environmental Engineering, \\ Engineering College of Gipuzkoa, University of the Basque Country (UPV/EHU), \\ 20018 Donostia-San Sebastián, Spain \\ fInstituto de Química, Universidade de São Paulo (USP), 05508-000 São Paulo-SP, Brazil
}

\begin{abstract}
Upconversion nanoparticles (UCNPs) are suitable materials for bioapplications due to their ability to emit visible light under near infrared (NIR) excitation, in the biological transparency range. Polycaprolactone(PCL)-based scaffolds are widely used in tissue engineering in combination with inorganic compounds to improve bioactivity and osteoconductive properties. This work proposes a $3 \mathrm{D}$ printed composite scaffold with upconversion property aiming at biomedical applications in therapy-stimulated bone repair and photodynamic therapy (PDT). The system combines PCL polymer, UCNPs-apatite and a PDT photosensitizer. Thermal and rheological behaviors of the composite were similar to pure PCL polymer. Mechanical properties were improved by adding UCNPs-apatite. The 3D printable composite presented upconversion property and potential for PDT application, which was demonstrated by singlet oxygen generation under $980 \mathrm{~nm}$ excitation. Cytotoxicity, genotoxicity and mutagenicity assays indicated no toxicological effects at low concentrations of rare earth elements. Taken together, a potential multifunctional material is proposed for biomedical applications.
\end{abstract}

Keywords: upconversion nanoparticles, photodynamic therapy, tissue engineering, 3D printing

\section{Introduction}

Lanthanide $\left(\mathrm{Ln}^{3+}\right)$-doped upconversion nanoparticles (UCNPs) have emerged as an attractive luminescent material due to their excellent optical properties related to their ability to convert low-energy near-infrared (NIR) light into high-energy UV or visible light in a process that involves the sequential absorption of photons. ${ }^{1}$ Application

*e-mail: karina.nig@gmail.com; sidney.jl.ribeiro@unesp.br

\#The authors contributed equally to this work. trends of UNCPs in literature involve analytes detection, ${ }^{2}$ nanothermometry, ${ }^{3}$ photovoltaic cell, ${ }^{4}$ and photocatalytic systems. ${ }^{5}$ Concerning the biomedical field, several bioapplications were reported in bioimaging platforms, ${ }^{6}$ thermal cellular imaging, ${ }^{7}$ bioassay, ${ }^{8}$ biosensing, ${ }^{9}$ disease detection, ${ }^{10}$ drug delivery systems, ${ }^{11}$ light activated therapies, ${ }^{12}$ and theranostic platforms. ${ }^{13}$ The unique advantages of UCNPs for diagnostic and therapeutic purposes are related with the possibility to excite them with low power and inexpensive continuous wave lasers operating in the NIR. Such excitation wavelength is 
inserted in the biological transparency window, and consequently offers deep light penetration into the tissues, low autofluorescence and low phototoxicity in comparison with conventional luminescent bioprobes, organic dyes and quantum dots, which require an excitation source in the UV-Visible region. In addition, UCNPs allow multiplexed biological labeling under a single excitation wavelength by changing activator ions and relative dopant concentrations. Capabilities for the simultaneous imaging and tracking of multiple molecular targets are therefore extended, allowing the classification and differentiation of complex human diseases. ${ }^{14}$ Furthermore, such $\mathrm{Ln}^{3+}$-based materials present long lifetimes that guarantee the indirect NIR activation of photosensitizers (PSs) used in photodynamic therapy (PDT), which are typically excited by UV-Visible light. ${ }^{15}$

PDT is an emerging and minimally invasive clinical method for the treatment of various types of diseases, such as cancer. This therapeutic approach consists in the use of a nontoxic PS and light irradiation at a specific wavelength leading to cell death resulting from oxidative damage. ${ }^{16}$ Conventional PDT usually requires high energy light (UV or visible) for PS activation, which can generate damage to healthy tissues. The use of lower energy NIR light for activation is a promising solution to avoid intensive damages to normal surrounding cells. Additionally, since NIR excitation light penetrates deeper through the tissues, it allows a higher volume to be treated in a single therapeutic session. ${ }^{17}$ However, NIRabsorbing PSs present some restrictions, such as the difficult synthesis of stable compounds. ${ }^{18}$ Moreover, triplet state of PS must be energetically higher than the singlet level of oxygen molecule to allow the energy transfer to take place. The use of UCNPs for PS-sensitization under NIR represents a potential alternative to overcome such limitations. ${ }^{19}$

The current need for multifunctional materials able to perform diagnosis and therapy simultaneously count on the combination of luminescent nanoparticles with ceramics and polymers to obtain synergistic properties. ${ }^{20}$ In the case of three-dimensional (3D) structured scaffolds for replacement/reconstruction of tissues or organs the choice of the component materials must consider several factors such as non-toxicity, biocompatibility and suitable physical and mechanical properties for inducing tissue neoformation according with the properties of the tissue to be regenerated. ${ }^{21}$ In this context, additive manufacturing (AM), also known as 3D printing, is a promising technology for scaffolds manufacturing wherein implants need to have anatomically accurate characteristics to defect, e.g., bone substitutes..$^{22}$ This technology allows for a better control of porosity, pore size, high geometric complexity, well-defined architecture, as well as patient-specific implant designs than other established scaffold manufacturing methods. ${ }^{23}$ Owing to this versatility, the $3 \mathrm{D}$ printing has been widely used to scaffolds manufacturing for replacement or reconstruction of complexes tissues or organs..$^{24}$

Polycaprolactone (PCL) is one of the most commonly used synthetic polymers in the synthesis of composites materials due to its easy processability in a wide temperature range (glass transition temperature $\left(\mathrm{T}_{\mathrm{g}}\right)$ ca. 65 to $70{ }^{\circ} \mathrm{C}$; onset temperature $\left(\mathrm{T}_{\text {onset }}\right)$ ca. $\left.300{ }^{\circ} \mathrm{C}\right)$ and its great compatibility with other polymers to obtain blends. ${ }^{25} \mathrm{In}$ addition, PCL is an aliphatic and semi-crystalline polyester with slow in vivo degradation rate. ${ }^{26}$ PCL-based scaffolds are used in tissue engineering for the growth of a variety of tissue types, such as skin, ${ }^{27}$ nerve,,${ }^{28}$ mammary glands, ${ }^{29}$ bone, ${ }^{30}$ and so forth. In order to improve bioactivity and osteoconductive properties of synthetic polymers, inorganic compounds have been incorporated into their polymeric constituent matrices. ${ }^{31}$ PCL-based composites containing hydroxyapatite, $\mathrm{Ca}_{10}\left(\mathrm{PO}_{4}\right)_{6}(\mathrm{OH})_{2}{ }^{32}$ or other calcium phosphate derivatives, such as octacalcium phosphate, ${ }^{33}$ and tricalcium phosphate, ${ }^{34}$ have demonstrated to improve the mechanical properties, bioactivity, biodegradability and biocompatibility of PCL. ${ }^{35}$ Hence, PCL-based composites are potential candidate materials for $3 \mathrm{D}$ printing and bone tissue engineering.

Filipovic et al.,$^{36}$ evaluating the toxic potential of PCL nanospheres associated with poly (glutamic acid) (PGA) at different concentrations, found that PCL without PGA, PCL containing 0.5 or $1 \%$ PGA did not significantly reduce the viability of HepG2 cells by the MTT assay, i.e., the tetrazolium dye 3-(4,5-dimethylthiazol-2-yl)2,5-diphenyltetrazolium bromide. The authors concluded that PCL nanoparticles did not show significant cytotoxicity. The genotoxic character was evaluated by the comet assay regarding the PCL without PGA, PCL containing 0.05, 0.5 or $1 \%$ of PGA for $24 \mathrm{~h}$. The PCL sample without PGA was genotoxic at concentrations of $0.01 ; 0.1$ and $1 \%$, but no significant deoxyribonucleic acid (DNA) damage was observed at concentrations of 0.001 and 0.0001 . Wang et al $^{37}$ evaluated the cytotoxic and mutagenic potential of a PCL material in its composition: thermosensitive hydrogel material composed of poly ( $\varepsilon$-caprolactone-co-1,4,8-trioxa [4.6] spiro-9-undecanone)-PEG-poly( $\varepsilon$-caprolactone-co1,4,8-trioxa [4.6] spiro-9-undecanone) (PECT), a copolymer of nanoparticles that can be used for the release of drugs to treat some types of cancer. ${ }^{37}$ The authors used the MTT assay to quantitatively assess the L929 cell viability and demonstrated that in the concentration range of 10 to $500 \mu \mathrm{g} \mathrm{mL}^{-1}$ of the PECT nanoparticle solution, there were no cytotoxicity since the cell viability was around $100 \%$. The mutagenic potential of the PECT nanoparticles was negative for both the in vivo micronucleus test and the 
reverse mutation test in bacteria (Ames test). For the in vivo micronucleus test, intravenous PECT nanoparticle dispersion treatment at doses of 0.5 and $1.0 \mathrm{~g} \mathrm{~kg}^{-1}$ body weight were carried out, with the smear of the femoral bone of the rats stained by Giemsa. No significant increase of micronucleus in polychromatic and normochromatic erythrocytes was observed with the treatment of the PECT nanoparticles in comparison to the negative control. The Ames test was performed according to the standard Ames protocol, using mutant strains of Salmonella typhimurium incubated with various concentrations of nanoparticles $(0.05,0.5$ or $5 \mathrm{mg}$ per plate) in the presence or absence of metabolic activation. The authors verified that the PECT nanoparticles were not mutagenic to the studied strains. The authors concluded, after the results of the Ames and micronucleus tests, that the PECT nanoparticles did not promote mutagenicity. Thus, in this study of PCL associated with other materials constituting a copolymer of nanoparticles, did not present mutagenic potential. Ramasamy et al. ${ }^{38}$ investigating $\mathrm{NaGdF}_{4}: \mathrm{Yb}^{3+}: \mathrm{Er}^{3+}$ nanoparticles that have been successfully applied to HeLa fluorescent imaging cells, performed the MTT test at concentrations of $0,100,250,500$ and $1000 \mathrm{mg}$. No significant difference was observed in the cell proliferation at different concentrations, which estimated a cell growth greater than $89 \%$ after $24 \mathrm{~h}$ of treatment with the nanoparticles. The results of the MTT assay clearly showed that the nanoparticles containing $\mathrm{Yb}^{3+}$ and $\mathrm{Er}^{3+}$ demonstrated low cytotoxicity for HeLa cells.

The present study aimed to synthesize a multifunctional composite for medical applications based on UCNPs $\left(\mathrm{YVO}_{4}: \mathrm{Yb}^{3+}: \mathrm{Er}^{3+}\right)$, apatite and $\mathrm{PCL}$ obtained by $3 \mathrm{D}$ printing. Our multifunctional composite, labeled as PCL/UCNPsapatite, demonstrated superior features compared with previous PCL-based composites reported in literature, ${ }^{39}$ concerning high radiopacity, upconversion luminescence and superior mechanical properties compared with UCNPs-apatite. The incorporation of a PDT photosensitizer in PCL/UCNPs-apatite was performed and the energy transfer from UCNPs emission to PS was demonstrated by the characteristic visible PS emission under $980 \mathrm{~nm}$ excitation. Furthermore, the PDT efficacy was demonstrated by singlet oxygen generation under NIR irradiation. The toxicological effects have been investigated in detail.

\section{Experimental}

\section{Materials}

Materials used in this work were dialysis tubing cellulose membrane with a molecular weight cut off of 14 kDa (Sigma-Aldrich, St. Louis, USA), PCL 37,000 $\left(\right.$ CAPA $^{\circledR}$ 6505, Solvay, Warrington, UK), erythrosine B (Aldrich, St. Louis, USA), deuterium oxide $99.9 \%$ (Sigma-Aldrich, St. Louis, USA), culture medium (Sigma ${ }^{\circledR}$, St. Louis, USA), Dulbecco's Modified Eagle's (D-MEM) medium (Sigma ${ }^{\circledR}$, St. Louis, USA), fetal bovine serum (Cultilab, Campinas, Brazil), antibiotic antimycotic solution (Sigma $^{\circledR}$, St. Louis, USA), Cell Proliferation Kit II (XTT, Roche Applied Science, Indianapolis, USA), Microplate Reader (VersaMax, Molecular Devices, Sunnyvale, USA), microscope slides (Knittel, Braunschweig, Germany), normal melting point agarose (Gibco, Paisley, Great Britain). Other reagents were purchased from Sigma Aldrich (St. Louis, USA) in analytical grade and stored properly.

\section{Synthesis}

\section{Apatite}

Apatite was synthesized from a stoichiometric mixture composed of $\mathrm{CaCO}_{3}$ (50 wt.\%), $\left(\mathrm{NH}_{4}\right)_{2} \mathrm{HPO}_{4}(50 \mathrm{wt} . \%)$ by high-temperature solid-state reaction. First, the stoichiometric mixture was refined by ball-milling process using a raw powder: ethanol ratio $\left(2: 1, \mathrm{~g} \mathrm{~mL}^{-1}\right)$. After sintering, the product was crushed and then wetly ballmilled again for $24 \mathrm{~h}$. The sintering steps and parameters were at $950{ }^{\circ} \mathrm{C}$ for $2 \mathrm{~h}$ and then at $1100{ }^{\circ} \mathrm{C}$ for $48 \mathrm{~h}$, with a heating ramp of $5{ }^{\circ} \mathrm{C} \mathrm{min}{ }^{-1}$ and a cooling ramp of $10{ }^{\circ} \mathrm{C} \mathrm{min}{ }^{-1}$ down to room temperature.

\section{$\mathrm{YVO}_{4}: \mathrm{Yb}^{3+}: \mathrm{Er}^{3+}$ nanoparticles}

$\mathrm{YVO}_{4}: \mathrm{Yb}^{3+}: \mathrm{Er}^{3+}$ upconversion nanoparticles (UCNPs) were synthesized according to the method previously reported by Nigoghossian et al..$^{40}$ The method consists in a co-precipitation of sodium citrate $2 \mathrm{M}(5 \mathrm{~mL})$ and lanthanide ions. The latter is a mixture of aqueous solutions (1 M) of yttrium nitrate and ytterbium and erbium chlorides in a defined molar ratio ( $\mathrm{Y}: \mathrm{Yb}: \mathrm{Er}=77.5: 20: 2.5)$. After $1 \mathrm{~h}$ of stirring at room temperature, the precipitate of lanthanide citrate complex was dissolved by adding an aqueous solution of vanadate precursor, $\mathrm{Na}_{3} \mathrm{VO}_{4}(0.2 \mathrm{M}$, $50 \mathrm{~mL}$ ). The reaction medium was kept under stirring at $60{ }^{\circ} \mathrm{C}$ for $45 \mathrm{~min}$. Unreacted ions were removed by dialysis against water performed for $72 \mathrm{~h}$. The purified nanoparticle solution was lyophilized, and the powder was heat treated at $1000{ }^{\circ} \mathrm{C}$ for $60 \mathrm{~min}$.

\section{UCNPs-apatite}

Apatite doped in $5 \mathrm{wt} . \%$ with UCNPs was synthesized in a similar way described above, but starting from a stoichiometric mixture composed of $\mathrm{CaCO}_{3}(50 \mathrm{wt} . \%)$, $\left(\mathrm{NH}_{4}\right) \mathrm{HPO}_{4}(45 \mathrm{wt} . \%)$ and UCNPs $(5 \mathrm{wt} . \%)$. 


\section{PCL/UCNPs-apatite}

PCL-based composite containing 12.5 wt.\% of UCNPs-apatite was prepared from a homogeneous premixing powders of PCL and UCNPs-apatite. Then, the composite was processed using a twin-screw extruder (HAAKETM MiniLab Microcompounder, ThermoScientificTM), with a screw speed of $50 \mathrm{rpm}$ and temperature process of $100{ }^{\circ} \mathrm{C}$. The extruded composite was subjected to the pelletizing step. A second extrusion was performed with extruded pellets for ensuring a better homogenization of the UCNPs-apatite particles with the polymer, using the same process parameters of first extrusion. Hence, the PCL/UCNPs-apatite composite was obtained as standardized filaments in 1.7-1.8 mm diameter.

\section{D printing of PCL/UCNPs-apatite scaffolds}

Cylindrical and cuboid scaffold models with a 3D orthogonal-projection porous architecture were designed using SolidWorks ${ }^{\circledR}$ software. ${ }^{41}$ CAD model for in vitro assays was designed in the following dimension, $11 \times 2 \mathrm{~mm}$ (diameter $\times$ height), and CAD model cuboid scaffold, $20 \times 20 \times 2 \mathrm{~mm}$ (length $\times$ width $\times$ height). Struts and pores were designed in size of $500 \mu \mathrm{m}$, which provided a porous structure with interconnected pores. The 3D scaffolds were manufactured by a filament extrusion technology (fused filament fabrication (FFF)) using a Fab@CTI printer (Centro de Tecnologia da Informação Renato Archer, CTI, Campinas, Brazil). Fab@Home v0.24 rc6 software was used to manufacture the 3D model by layer-by-layer fabrication process. ${ }^{42}$ The nozzle used to extrude PCL/UCNPs-apatite composite filaments was a stainless-steel needle characterized by an inner diameter of $400 \mu \mathrm{m}$. The printing parameters used were: temperature $=90{ }^{\circ} \mathrm{C}$; deposition rate $=0.15 \mathrm{~mm} \mathrm{~s}^{-1}$; path width $=0.40 \mathrm{~mm}$; path height $=0.35 \mathrm{~mm}$; path speed $=9 \mathrm{~mm} \mathrm{~s}^{-1}$.

\section{Characterizations}

UCNPs-apatite and the PCL/UCNPs-apatite composite, extruded filament and 3D-printed scaffold were characterized in terms of morphological, structural, thermal, mechanical and emission properties. UCNPs-apatite powder was analyzed in $\mathrm{KBr}$ pellet by Fourier transform infrared spectroscopy (FTIR) using a Thermo Scientific Nicolet IS5 equipment with an iD1 transmission module. Twenty scans were acquired in the 4000 to $500 \mathrm{~cm}^{-1}$ range with a resolution of $2 \mathrm{~cm}^{-1}$. In order to verify the distribution of UNCPsapatite in polymer matrix, the down-shifted emission of erbium was observed by using the luminescence microscope (EVOS FL-AMG) with wavelength of excitation at $470 \mathrm{~nm}$ and emission at $525 \mathrm{~nm}$. The PCL/UCNPs-apatite composite was characterized by differential scanning calorimetry (DSC), rheology testing and dynamic mechanical analysis (DMA). DSC analyses of the composite and PCL filaments were performed using a differential scanning calorimeter Q100 DSC (TA Instruments). The samples were heated in hermetic aluminum pans under nitrogen atmosphere (flow rate: $50 \mathrm{~mL} \mathrm{~min}{ }^{-1}$ ) at a heating rate of $10{ }^{\circ} \mathrm{C} \mathrm{min}^{-1}$. First heating cycle was performed from 25 to $100{ }^{\circ} \mathrm{C}$ in order to erase the thermal history of the materials. In sequence, the samples were cooled at a rate of $10^{\circ} \mathrm{C} \mathrm{min}^{-1}$ until $0{ }^{\circ} \mathrm{C}$. Finally, a second heating cycle was performed from 0 to $100{ }^{\circ} \mathrm{C}$. The thermal transitions and the enthalpy of fusion were obtained from DSC curves in the cooling step and in the second heating. The following parameters were determined: crystallization temperature $(\mathrm{Tc})$, onset temperature $\left(\mathrm{T}_{\text {onset }}\right)$, melting temperature $(\mathrm{Tm})$ and degree of crystallinity $(\mathrm{Xc})$. The steady state rheological properties of the PCL/UCNPsapatite composite and PCL polymer were investigated using a controlled-stress rheometer AR-G2 (TA Instruments). The measurements for the melt samples were performed using parallel plates with $25 \mathrm{~mm}$ of diameter and a gap of $1 \mathrm{~mm}$, under nitrogen atmosphere, at $100^{\circ} \mathrm{C}$ (extrusion temperature of the composite). Stress overshoot tests were performed prior to steady state experiments. Curves of viscosity as a function of shear rate were measured in a range from 0.01 to $100 \mathrm{~s}^{-1}$. DMA analyses were performed using a Q800 DMA (TA Instruments) to obtain the storage modules of the samples under flexural strain. The samples were molded in a hot press at $100{ }^{\circ} \mathrm{C}$ with rectangular geometry $(40 \times 12 \times 3 \mathrm{~mm})$. DMA measurements were done using a single-cantilever fixture at $37^{\circ} \mathrm{C}$, amplitude strain of $15 \mu \mathrm{m}$, in a frequency range from 0.1 to $10 \mathrm{~Hz}$. Upconversion spectra of UCNPscontaining samples were obtained using a Horiba Jobin Yvon fluorimeter (iHR-320). A diode laser operating at $980 \mathrm{~nm}$ (DMC Equipment, São Carlos-SP, Brazil) coupled with a standard multimode fiber ( $50 \mu \mathrm{m}$ core diameter) was used as an excitation source. The fiber tip was positioned close to the sample, thus being the beam spot the same as the core diameter. The measurements were carried out under the same experimental conditions. The output power was estimated by using a power meter (Newport 2935-C). The maximum output power applied was $900 \mathrm{~mW}$. The maximum power density (power per area) of the laser beam was $45.8 \mathrm{~kW} \mathrm{~cm}^{-2}$. All measurements were performed at room temperature and corrected by the instrumental response.

\section{Cytotoxicity, genotoxicity and mutagenicity assays}

Pure PCL and the composite PCL/UCNPs-apatite were sterilized by $25 \mathrm{kGy}$ gamma radiation at the Brazilian 
Radiation Company (CBE Embrarad, Cotia, SP). The evaluation of pure PCL and PCL/UCNPs-apatite was performed in four different concentrations (PCL 100\%, PCL 75\%, PCL 50\%, PCL 25\%, PCL/UCNPs-apatite $100 \%$, PCL/UCNPs-apatite 75\%, PCL/UCNPs-apatite $50 \%$, PCL/UCNPs-apatite $25 \%$ ), obtained from the preparation of eluate, made according to ISO 10993-12.43 The material was immersed in HAMF10:D-MEN (1:1) culture medium without fetal bovine serum (FBS) at $37^{\circ} \mathrm{C}$ for $72 \mathrm{~h}$, shaking at $133 \mathrm{rpm}$ in an incubator (New Brunswick Scientific-Excella E24 Incubator Shaker Series).

\section{Cell culture experiments}

CHO-K1 cells were cultured in 1:1 Ham-F10 + D-MEM medium supplemented with $10 \% \mathrm{FBS}$ and antibiotic antimycotic solution in $25 \mathrm{~cm}$ culture flasks at $37{ }^{\circ} \mathrm{C}, 5 \%$ $\mathrm{CO}_{2}$. Cells were used between the third and eighth passages.

\section{Cytotoxicity tests}

\section{XTT assay}

After 24 h of seeding, CHO-K1 cells $\left(2 \times 10^{4}\right.$ cells seeded) were treated with eluates (in duplicate) for $24 \mathrm{~h}$ in 24-well plates. Each well containing eluate was supplemented with $10 \%$ FBS. Negative controls (NC) were wells with culture medium supplemented with $10 \%$ FBS in the absence of any eluate (untreated controls). For positive controls (PC) doxorubicin hydrochloride $\left(3.0 \mu \mathrm{g} \mathrm{mL} \mathrm{m}^{-1}\right.$ for $24 \mathrm{~h}$ ) was used. After treatment, the cultures were washed with PBS solution and fresh medium was added. After $24 \mathrm{~h}$ of incubation, the cultures were washed with PBS solution and immediately DMEM without phenol red was added $(500 \mu \mathrm{L})$, followed by the addition of the $\mathrm{XTT} /$ electron solution $(50: 1,60 \mu \mathrm{L})$. After $3 \mathrm{~h}$ reaction, the supernatant was transferred to a 96-well culture plate and the absorbance was measured by a microplate reader at 492 and $690 \mathrm{~nm}$. The absorbance is directly proportional to the number of viable cells in each treatment after $24 \mathrm{~h}$ of exposure. Three independent experiments were conducted.

\section{Clonogenic assay}

After $24 \mathrm{~h}$ of seeding, CHO-K1 cells $\left(4 \times 10^{4}\right.$ cells seeded) were exposed for $24 \mathrm{~h}$ to the eluates (in duplicate) for $24 \mathrm{~h}$ in 24-well plates. Each eluate well was supplemented with $10 \%$ FBS. Negative controls (NC) were wells with culture medium supplemented with $10 \%$ FBS in the absence of any eluate. Positive controls (PC) were treated with doxorubicin hydrochloride $\left(0.3 \mu \mathrm{g} \mathrm{mL}{ }^{-1}\right)$ for $4 \mathrm{~h}$. After exposure, the cultures were washed with PBS solution and fresh medium was added. Exponentially growing cells were seeded after treatment at a number of 150 cells per $25 \mathrm{~cm}$ flasks, in duplicate for each treatment. The flasks were incubated at $37{ }^{\circ} \mathrm{C}, 5 \% \mathrm{CO}_{2}$, for 7 days without medium exchange. The colonies were fixed with methanol:acetic acid:water $(1: 1: 8, \mathrm{v} / \mathrm{v} / \mathrm{v})$ and stained with $5 \%$ Giemsa. The colonies were visually counted, and the cell surviving fraction was calculated as percent colonies in treated flasks relative to untreated controls (NC). Three independent experiments were conducted.

\section{Genotoxicity evaluation}

\section{Comet assay}

The alkaline version of the comet assay was used according to the methodology described by Singh et al. ${ }^{44}$ After $24 \mathrm{~h}$ of seeding, cells $\left(4 \times 10^{4}\right.$ cells seeded) were exposed to the eluates in 24-well plates. Negative controls (NC) were wells with culture medium supplemented with $10 \%$ FBS in the absence of any eluate, while positive controls (PC) were treated with hydrogen peroxide $\left(80 \mu \mathrm{mol} \mathrm{L}{ }^{-1}\right.$ for $10 \mathrm{~min}$ ) (all experiments were carried out in duplicate). After exposure, the cultures were washed with PBS solution and harvested with trypsin. Five hundred microliters of cells in suspension were obtained, kept on ice and protected from light. After centrifugation, the pellet was resuspended in $0.5 \%(\mathrm{~m} / \mathrm{v})$ low melting point agarose $(200 \mu \mathrm{L})$ and the mixture were spread onto two microscope slides pre-coated with $1.5 \%(\mathrm{~m} / \mathrm{v})$ normal melting point agarose. Coverslips were placed over the gel. When the gels had solidified in the refrigerator, the coverslips were gently removed and the slides were immersed in a cold $\left(4{ }^{\circ} \mathrm{C}\right)$ lysis solution (1\% Triton $\mathrm{X}-100,10 \%$ dimethyl sulfoxide (DMSO), $2.5 \mathrm{mmol} \mathrm{L}^{-1}$ $\mathrm{NaCl}, 100 \mathrm{mmol} \mathrm{L}^{-1}$ disodium ethylenediaminetetraacetate dihydrate $\left(\mathrm{Na}_{2}\right.$ EDTA), $100 \mathrm{mmol} \mathrm{L}^{-1}$ Tris, $\mathrm{pH} 10$ ) for $24 \mathrm{~h}$. Immediately after this step, slides were placed in a horizontal electrophoresis unit containing freshly prepared electrophoresis buffer $\left(1 \mathrm{mmol} \mathrm{L}^{-1} \mathrm{Na}_{2}\right.$ EDTA, $300 \mathrm{mmol} \mathrm{L}^{-1}$ $\mathrm{NaOH}, \mathrm{pH}>13$ ). The DNA was allowed to unwind for $20 \mathrm{~min}$ and subsequently electrophoresis was performed at $43 \mathrm{~V}, 308 \mathrm{~mA}$ for $25 \mathrm{~min}$. Afterward, the slides were gently immersed in neutralization buffer $\left(0.4 \mathrm{~mol} \mathrm{~L}^{-1}\right.$ Tris- $\mathrm{HCl}$, $\mathrm{pH}$ 7.5) for $15 \mathrm{~min}$, protected from light in a refrigerator and then fixed with ethanol. Three independent experiments were conducted. DNA damage was determined in a blind test in 100 nucleoids per slide. Duplicate slides were prepared, stained with ethidium bromide, and screened with a fluorescent microscope (ZEISS ${ }^{\circledR}$, Jena, Thuringia, DEU) equipped with an excitation filter of 515-560 nm, a barrier filter of $590 \mathrm{~nm}$ and a 40x objective. The level of DNA damage was assessed by an image analysis system 
(TriTek CometScore ${ }^{\circledR}$ 1.5, 2006, Sumerduck, VA, USA), and the DNA percentage in the tail and tail moment were obtained for each treatment.

Mutagenicity evaluation

\section{Cytokinesis-blocked micronucleus (CBMN) assay}

CBMN assay was performed according to Fenech et al..$^{45}$ with minor modifications. $\mathrm{CHO}-\mathrm{K} 1$ cells $\left(37 \times 10^{4}\right.$ cells $\mathrm{per}$ culture flask) were seeded in $25 \mathrm{~cm}^{2}$ culture flasks at $37{ }^{\circ} \mathrm{C}$, $5 \% \mathrm{CO}_{2}$. After $24 \mathrm{~h}$ of seeding, cells were exposed for $24 \mathrm{~h}$ to the eluates (in duplicate). Each eluate culture flask was supplemented with $10 \%$ FBS. Negative controls (NC) were culture flasks with culture medium supplemented with $10 \%$ FBS in the absence of any eluate (untreated controls), while positive controls (PC) were treated with doxorubicin hydrochloride $\left(0.15 \mu \mathrm{g} \mathrm{mL}^{-1}\right)$ for $4 \mathrm{~h}$. Cytochalasin-B $(\mathrm{CytB})$ was added to the $\mathrm{CHO}-\mathrm{K} 1$ cultures at a final concentration of $25 \mu \mathrm{L}$ of cytochalasin B ( $\left.1 \mathrm{mg} \mathrm{mL}^{-1}\right)$ for $24 \mathrm{~h}$ to stop cytokinesis. After treatments, the cultures were washed with PBS solution, trypsinized and centrifuged for $7 \mathrm{~min}$ at $1000 \mathrm{rpm}$. The pellet was then resuspended in cold hypotonic solution $(0.3 \% \mathrm{KCl}, \mathrm{m} / \mathrm{v})$ for $5 \mathrm{~min}$. Cells were fixed twice with methanol:glacial acetic acid $(3: 1, \mathrm{v} / \mathrm{v})$ and with four drops of formaldehyde, and then homogenized carefully with a Pasteur pipette. The cell suspensions were dripped on a slide with a film of distilled water at $4{ }^{\circ} \mathrm{C}$. The slides were stained with $5 \%$ Giemsa solution diluted in phosphate buffer (0.06 mol L-1 $\mathrm{Na}_{2} \mathrm{HPO}_{4}, 0.06 \mathrm{~mol} \mathrm{~L}^{-1} \mathrm{KH}_{2} \mathrm{PO}_{4}, \mathrm{pH}$ 6.8) for $7 \mathrm{~min}$, washed with distilled water and dried at room temperature. For the determination of the nuclear division index (NDI), 500 viable cells with well-preserved cytoplasm were analyzed using a Leica DM500 microscope, using the formula: $[\mathrm{NDI}=\mathrm{M} 1+2(\mathrm{M} 2)+3(\mathrm{M} 3)+4(\mathrm{M} 4) / \mathrm{N}]$, where M1-M4 represents the number of cells with 1-4 nuclei, respectively, and $\mathrm{N}$ is the total number of viable cells scored. Frequency of binucleated cells with micronuclei (MNBCF) and the total frequency of micronuclei (MNF) were scored in 1000 binucleated cells. The criteria used for identifying micronuclei were based on Fenech et al. ${ }^{45}$ Three independent experiments were conducted. ${ }^{45}$

\section{Statistical analysis}

The results were expressed as mean and standard error. For the parametric data, one-way analysis of variance (ANOVA) followed by Tukey's test was applied. Data from treated groups were compared with the negative control using Dunnett's test. For non-parametric results, both Kruskall-Wallis test followed by Dunn's test were applied. The level of significance was 5\%. GraphPad Prism 5.01 Program $^{46}$ was used to perform the tests.

\section{PDT assays}

The PCL/UCNPs-apatite composite was prepared containing the photosensitizer (PS) erythrosine B to study the capability of this material to generate singlet oxygen under near-infrared irradiation. Erythrosine-containing PCL/UCNPs-apatite composite (hereafter named PS-PCL/UCNPs-apatite) was prepared following a modified protocol described above, in "PCL/UCNPsapatite" sub-section. After mixing PCL and UCNPs-apatite powders, PS solution in ethanol was added $(100 \mu \mathrm{L}$, $1 \mu \mathrm{M})$ to the preprocessed material. The mixture was homogenized and then extruded. For comparison purposes, a free-UCNPs-apatite sample was prepared (PS-PCL) by combining photosensitizer and PCL polymer.

The generation of singlet oxygen was determined by means of time-resolved phosphorescence analysis. Lifetime was calculated from kinetic analysis phosphorescence decay curves of ${ }^{1} \mathrm{O}_{2}$ at $1270 \mathrm{~nm}$. Decay curves were recorded with a time-resolved NIR fluorometer (Edinburgh Analytical Instruments) equipped with a Nd:YAG laser (Quantel, Rainbow) emitting at $1064 \mathrm{~nm}$ adjusted for the second $(532 \mathrm{~nm})$ and third $(355 \mathrm{~nm})$ harmonics with a pulse duration of 5-8 ns and a repetition rate of $10 \mathrm{~Hz}$. A tunable optical parametric oscillator (OPO, Quantel, Rainbow) provided the excitation wavelength at $980 \mathrm{~nm}$. An $850 \mathrm{~nm}$ long-pass filter (Thor Labs FGL850) was placed between laser excitation and sample. The emitted light was detected by photomultiplier (Hamamatsu Co. R5509) cooled by liquid nitrogen $\left(-80^{\circ} \mathrm{C}\right)$ and raw data were processed using F980 acquisition software (Edinburg Instruments). ${ }^{47}$ The measurements were performed in $\mathrm{D}_{2} \mathrm{O}$ to increase the ${ }^{1} \mathrm{O}_{2}$ lifetime and under air-equilibrated conditions.

\section{Results and Discussion}

Tissue engineering is an interdisciplinary field aimed at bioactive porous materials for repairing tissues affected by injury. ${ }^{26} 3 \mathrm{D}$-printed scaffolds have been widely used as a support for cell growth and proliferation. ${ }^{48}$ Such materials offer more familiar conditions mimetizing the characteristics of the target tissue environment, thus allowing the biological activity of cells at their internal structure. ${ }^{49}$ Conventional techniques for 3D scaffolds manufacture such as salt leaching, gas foaming, fiber bonding, solvent casting, melting molding and phase separation have limitations related to porous control for migration and diffusion of cells and to avoid the production of interconnected structures for cell growth. ${ }^{23}$ The advances in computational science and its integration with biomaterials production and tissue engineering has brought new techniques for the development of the manufacturing 
process. Among these techniques, the additive manufacture (3D printing) consists in printing of $3 \mathrm{D}$ scaffolds in connection to a computer, allowing the construction of materials with precise control of shape, pore size, porosity, and even some patient-specific structure needs. ${ }^{23,50}$

The FTIR spectrum of the obtained UCNPs-apatite is shown on Figure 1, as well as the UCNPs and apatite spectra for comparison purposes. The bands present in all spectra located at 3435 and $1629 \mathrm{~cm}^{-1}$ are due to water molecules adsorbed on the materials. The apatite characteristic bands associated to $\mathrm{PO}_{4}{ }^{3-}$ groups are located at 1129, 1031, 849,607 and $546 \mathrm{~cm}^{-1}$. The bands related to calcium are below $400 \mathrm{~cm}^{-1}$, out of the spectral region of equipment detection. ${ }^{51}$ Bands at $812 \mathrm{~cm}^{-1}$ and the shoulder at $904 \mathrm{~cm}^{-1}$ observed in UCNPs spectrum refer to $\mathrm{VO}_{4}{ }^{3-}$ group present in host matrix of $\mathrm{YVO}_{4}: \mathrm{Yb}^{3+}: \mathrm{Er}^{3+}$ nanoparticles. For UCNPs-apatite, such bands appear on the shoulders at 941, 968, 852 and $842 \mathrm{~cm}^{-1} .{ }^{52}$ The UCNPs-apatite presents the characteristic bands of both apatite and UNCPs, suggesting no alteration of these phases during the synthesis.

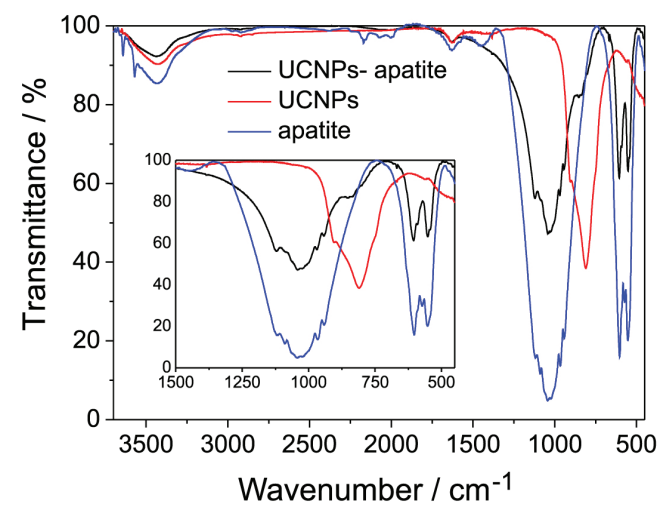

Figure 1. FTIR spectra of UCNPs-apatite, UCNPs and apatite. Inset enlarges the $1500-450 \mathrm{~cm}^{-1}$ region for the exploration.

The DSC analysis of PCL and PCL/UCNPs-apatite rendered the values of melting temperature, onset temperature (when the sample starts melting), melting enthalpy and degree of crystallinity, displayed in Table 1. The measurements were performed up to $100{ }^{\circ} \mathrm{C}$, which represents the working temperature for both extrusion and printing processes. The results obtained from the DSC curves (Figure S5, Supplementary Information (SI) section) suggest that the thermal properties of PCL were not modified after the addition of the UCNPs-apatite. The melting temperature of the polymer remains close to $57{ }^{\circ} \mathrm{C}$ and no significant change in the melting peak was observed. The degree of crystallinity did not increase in the presence of apatite, but the crystallization process started at a slightly higher temperature $\left(35.3^{\circ} \mathrm{C}\right.$ for the composite and $32.4{ }^{\circ} \mathrm{C}$ for only PCL). The polymer PCL was chosen due to its easy and low-cost processing, which is related to its low melting point. Thus, it is not necessary to spend high amount of energy or use complex equipment to produce a material from this polymer.

Table 1. Summary of DSC characteristic data of the PCL and PCL/UCNPs-apatite

\begin{tabular}{lcc}
\hline Thermal properties & PCL & PCL/UCNPs-apatite \\
\hline Crystallization temperature $\left(\mathrm{T}_{\mathrm{c}}\right) /{ }^{\circ} \mathrm{C}$ & 24.1 & 26.5 \\
Onset temperature $\left(\mathrm{T}_{\text {onse }}\right) /{ }^{\circ} \mathrm{C}$ & 53.0 & 52.6 \\
Melting temperature $\left(\mathrm{T}_{\mathrm{m}}\right) /{ }^{\circ} \mathrm{C}$ & 57.2 & 56.1 \\
Melting enthalpy $\left(\Delta \mathrm{H}_{\mathrm{f}}\right) /\left(\mathrm{J} \mathrm{g}^{-1}\right)$ & 35.0 & 34.4 \\
Degree of crystallinity $\left(\mathrm{X}_{\mathrm{c}}\right) / \%$ & 25.9 & 25.5 \\
\hline
\end{tabular}

PCL: polycaprolactone; PCL/UCNPs-apatite: polycaprolactone/UCNPsapatite composite material.

The rheological characterization was focused on the steady state, under low shear rates. Figure 2a shows the curves of viscosity versus shear rate for PCL and PCL/UCNPs-apatite composite. These curves describe the behavior of both materials at $100{ }^{\circ} \mathrm{C}$, in a range of shear rate from 0.1 to $100 \mathrm{~s}^{-1}$. The comprehension of the rheological behavior of a material provides useful information to adapt the setup parameters of process equipment. Materials with higher viscosity usually require higher thread energy or higher pressure for processing. The rheological behavior of PCL/UCNPs-apatite is similar to PCL, which represents a great advantage, since the polymer is easy to process and requires low processing temperature. Both materials have a Newtonian plateau with very close values, which may indicate weak interactions between the polymer chains and the inorganic particles. At a shear rate around $13 \mathrm{~s}^{-1}$ these materials pass from Newtonian to pseudoplastic fluid. The disentanglement of the PCL macromolecules under shear must be responsible for these behaviors, where some intermolecular interactions break down, reducing the viscosity. ${ }^{53}$

The stiffness of PCL and PCL/UCNPs-apatite was evaluated by dynamic mechanical analysis using a flexure fixture (single-cantilever). Measurements in the dynamic regime make it possible to determine viscoelastic properties such as storage modulus $\left(G^{\prime}\right)$ and loss modulus $\left(G^{\prime \prime}\right) .{ }^{54}$ Other mechanical properties such as tensile strength, elongation and modulus of elasticity can be used to compare mechanical performance of different polymers and to evaluate the effects of the addition of reinforcements, fillers and additives. ${ }^{55}$ Therefore, the comparison of the mechanical performance between the PCL/UCNPs-apatite and the PCL polymer is possible using their storage modules obtained by DMA. Figure $2 \mathrm{~b}$ shows the results 
obtained under flexural strain, at $37^{\circ} \mathrm{C}$. PCL has a storage modulus of $196 \mathrm{MPa}$, which is consistent with some results from the literature for solid and compact test bodies. ${ }^{56}$ The PCL/UCNPs-apatite showed an excellent performance in the flexural test, once it had a storage modulus of 576.8 $\mathrm{MPa}$, around 3 times higher than the PCL polymer. The increase of storage modulus for the composite PCL/UCNPs-apatite can be due to the stiffness of apatite. Akkouch et al. ${ }^{35}$ reported the enhancement of mechanical properties of a composite material collagen/hydroxyapatite/ poly(lactide-co- $\varepsilon$-caprolactone), after adding collagen and hydroxyapatite to PCL, because of stiffness and strength of hydroxyapatite. ${ }^{35,57}$ These results evidences that PCL/UCNPs-apatite is a very promising material to be used in bone regeneration of sites with higher mechanical loads.

The luminescence spectra of UCNPs, UCNPs-apatite and PCL/UCNPs-apatite scaffold are shown in Figure 3a. The main peaks at 525, 550 and $660 \mathrm{~nm}$ correspond to the $\mathrm{Er}^{3+}$ ion transitions: ${ }^{2} \mathrm{H}_{11 / 2} \rightarrow{ }^{4} \mathrm{I}_{15 / 2},{ }^{4} \mathrm{~S}_{3 / 2} \rightarrow{ }^{4} \mathrm{I}_{15 / 2}$ and ${ }^{4} \mathrm{~F}_{9 / 2} \rightarrow{ }^{4} \mathrm{I}_{15 / 2}$, respectively. ${ }^{58}$ The photograph displays the resultant green emission of scaffold irradiated under $980 \mathrm{~nm}$. The emission profile of UCNPs-apatite and the scaffold of PCL/UCNPs-apatite are similar to that of UCNPs, as

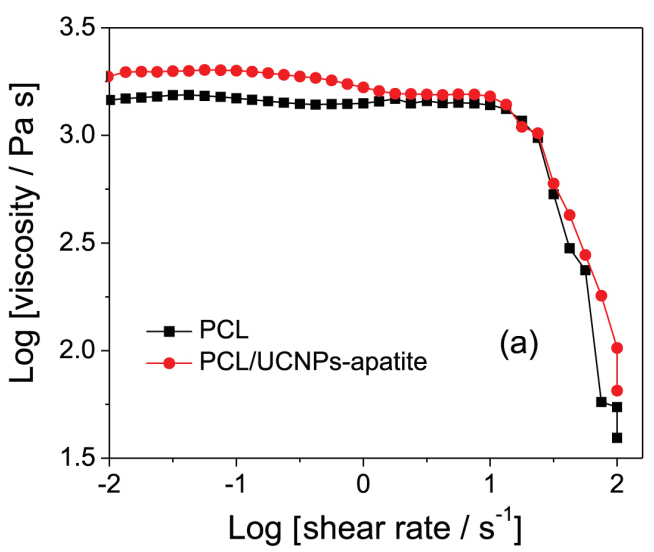

well as relative red-to-green intensity of emissions. This result is a demonstration that the incorporation of the luminescent material in apatite synthesis and 3D-printed scaffold production did not affect the emission properties of the particles. The Figure $3 b$ shows UNCPs-apatite distribution in PCL after its printing in the scaffold form. The green luminescence observed in the microscope image was obtained through the direct excitation at $470 \mathrm{~nm}$ to populate the ${ }^{4} \mathrm{~F}_{7 / 2}$ energy level of erbium. From this level, a non-radiative relaxation occurs to the next lower lying level ${ }^{2} \mathrm{H}_{11 / 2}$, and then a radiative transition ${ }^{2} \mathrm{H}_{11 / 2} \rightarrow{ }^{4} \mathrm{I}_{15 / 2}$ corresponds to the green emission at $525 \mathrm{~nm}$.

The luminescence observed through all the material indicates the homogeneous distribution of UCPs-apatite in PCL polymer. Some agglomerates can also be observed in the PCL/UCNPs-apatite, probably due to the weak interactions between both components, as discussed above in the rheological analyses.

The Figure 4a presents the PCL/UCNPs-apatite scaffold emission measured as a function of laser power. In upconversion process, the emission intensity $\left(\mathrm{I}_{\mathrm{em}}\right)$ is proportional to the intensity of pumping $\left(\mathrm{I}_{\mathrm{ex}}\right)$ according to the equation 1 :

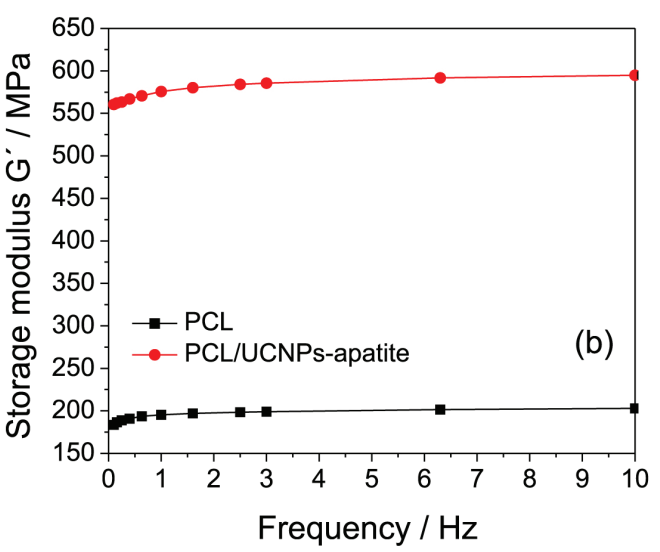

Figure 2. PCL and PCL/UCNPs-apatite. (a) Viscosity as a function of shear rate, at $100{ }^{\circ} \mathrm{C}$ and (b) storage modulus as a function of frequency, at $37{ }^{\circ} \mathrm{C}$.
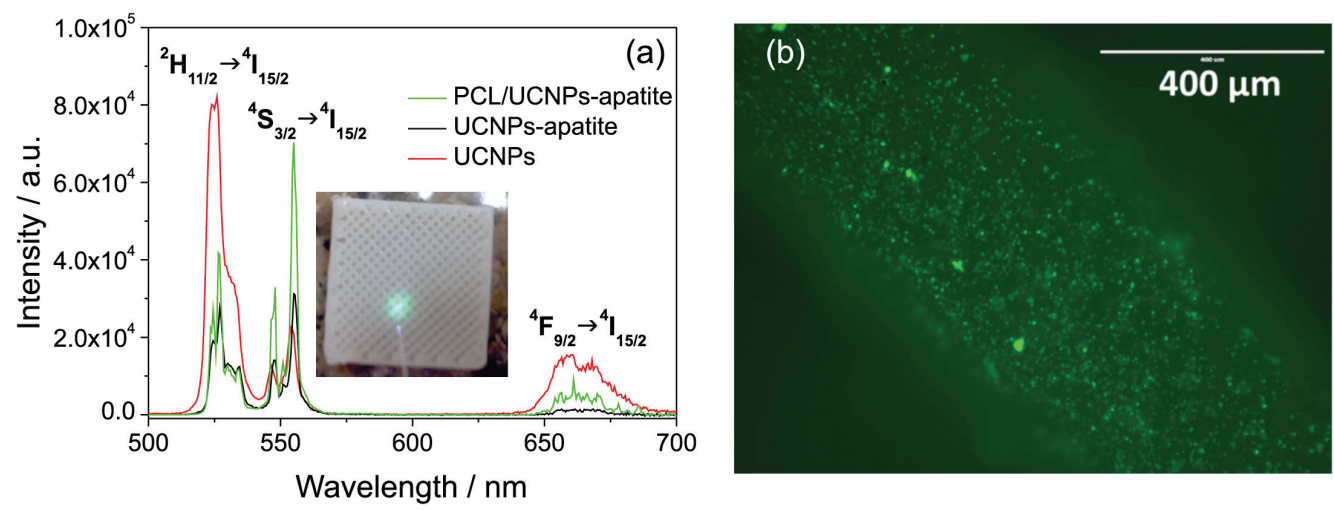

Figure 3. (a) Upconversion emission spectra $\left(\lambda_{\mathrm{ex}} 980 \mathrm{~nm}\right)$ of UCNPs, UCNPs-apatite and PCL/UCNPs-apatite. Inset: corresponding luminescent photograph of the material. (b) Luminescence microscope image of PCL/UCNPs-apatite scaffold. 
$I_{e m} \alpha\left(I_{e x}\right)^{n}$

where $\mathrm{n}$ is the number of absorbed infrared photons for the generation of a photon emitted in the visible, which can be obtained from the slope of the curve $\log \left(\mathrm{I}_{\mathrm{em}}\right) v s$. $\log \left(\mathrm{I}_{\mathrm{ex}}\right)$. The $\mathrm{n}$ value must necessarily be an integer number. However, thermal effects may decrease the slope to smaller values, since the excitation density is high enough to raise the temperature in the irradiated area decreasing the upconversion effect. ${ }^{59}$ Curves $\log \left(\mathrm{I}_{\mathrm{em}}\right)$ vs. $\log \left(\mathrm{I}_{\mathrm{ex}}\right)$ for green and red emissions of PCL/UCNPs-apatite scaffold are shown in Figure $4 \mathrm{~b}$ with respective $\mathrm{n}$ values. The obtained $n$ values indicate that two excitation photons are absorbed in NIR for a single visible photon emission. These data confirm the upconversion luminescence property of PCL/UCNPs-apatite system, evidencing the ability of this material to be excited under low energy and emit photons of larger energy in a multiphoton process. Taken together, PCL/UCNPs-apatite is a promising material to use for NIR-activation of photodynamic therapy process, besides to tissue engineering.

The utilization of the visible light emitted by up-conversion process under IR excitation to sensitize a photodynamic therapy photosensitizer was investigated for the erythrosine-containing PCL/UCNPs-apatite composite. The choice of this PS molecule was based on its characteristic absorption band between 460 and $560 \mathrm{~nm}$ that matches the green $\mathrm{Er}^{3+}$ emission. ${ }^{60}$ Moreover, erythrosine has been studied as an agent for antimicrobial PDT in dentistry applications. ${ }^{61}$ The PS was successfully incorporated in the PCL/UCNPs-apatite structure due to the high solubility of erythrosine in ethanol and the efficient homogenization during the material processing. The Figure 5a shows the photoluminescence excitation $\left(\lambda_{\mathrm{em}} 575 \mathrm{~nm}\right)$ and emission $\left(\lambda_{\mathrm{ex}} 551 \mathrm{~nm}\right)$ spectra obtained for PS-PCL/UCNPs-apatite and PS-PCL. The similar spectra profile presented by the free-UCNPs-apatite sample confirms that the bands are

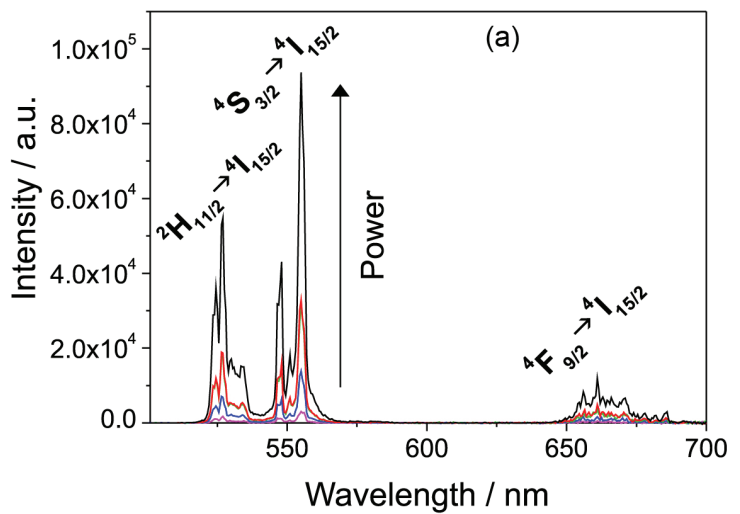

attributed to the photoluminescence of erythrosine. The excitation band (with maximum at $551 \mathrm{~nm}$ ) overlaps the region of $\mathrm{Er}^{3+}$ up-conversion emission of higher intensity in the visible region.

Figure $5 \mathrm{~b}$ presents the normalized emission spectra of PCL/UCNPs-apatite and PS-PCL/UCNPs-apatite composites under $980 \mathrm{~nm}$ excitation. The free-PS composite (PCL/UCNPs-apatite) presents lower red-to-green emission ratio compared with the $\mathrm{PS}$-containing composite (PS-PCL/UCNPs-apatite). This may be explained by the fact that the green up-converted emission is absorbed by the erythrosine molecules leading to the emission at $575 \mathrm{~nm}$ that can be clearly observed in the inset of Figure $5 \mathrm{c}$.

Singlet oxygen $\left({ }^{1} \mathrm{O}_{2}\right)$ generation by PS-PCL/UCNPsapatite composite in deuterium oxide was detected directly by measuring its characteristic phosphorescence at $1270 \mathrm{~nm}$ to detect the luminescence-decay kinetics. Singlet oxygen decay curves obtained from time-resolved luminescence measured under excitation at $980 \mathrm{~nm}$ are shown in Figure 5d. The inset shows the steady-state emission spectrum of ${ }^{1} \mathrm{O}_{2}$ that is known by being weak. ${ }^{62}$ The PS was not released to the environment under laser excitation. The ${ }^{1} \mathrm{O}_{2}$ lifetime was determined by fitting the decay with a biexponential function resulting in 0.48 and $5.64 \mu$ s values. Multiexponential behavior is sometimes observed for complex systems with different microenvironments. ${ }^{63}$ This result is an experimental proof-of-concept to demonstrate that the obtained PS-PCL/UCNPs-apatite composite is an efficient generator of singlet oxygen under NIR excitation.

The cytotoxicity results obtained by the XTT assay are presented in the Figure $6 a$. The absorbent axis is proportional to the number of metabolically active cells (viable cells), and the NC is considered as the reference of the Dunnett's test. Statistical difference was observed between NC and PC $(p<$ 0.05). All the eluate dilutions obtained from the PCL samples or the PCL/UCNPs-apatite composites were not cytotoxic, as they did not reveal a statistically significant difference in

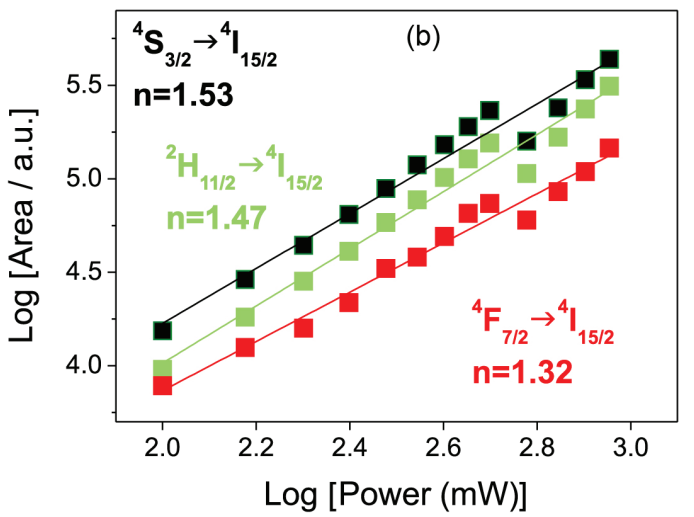

Figure 4. (a) Upconversion emission spectra $\left(\lambda_{\mathrm{ex}} 980 \mathrm{~nm}\right.$ ) of PCL/UCNPs-apatite scaffold as a function of laser power (100-900 mW). (b) Pump power dependence of the emission intensities. 

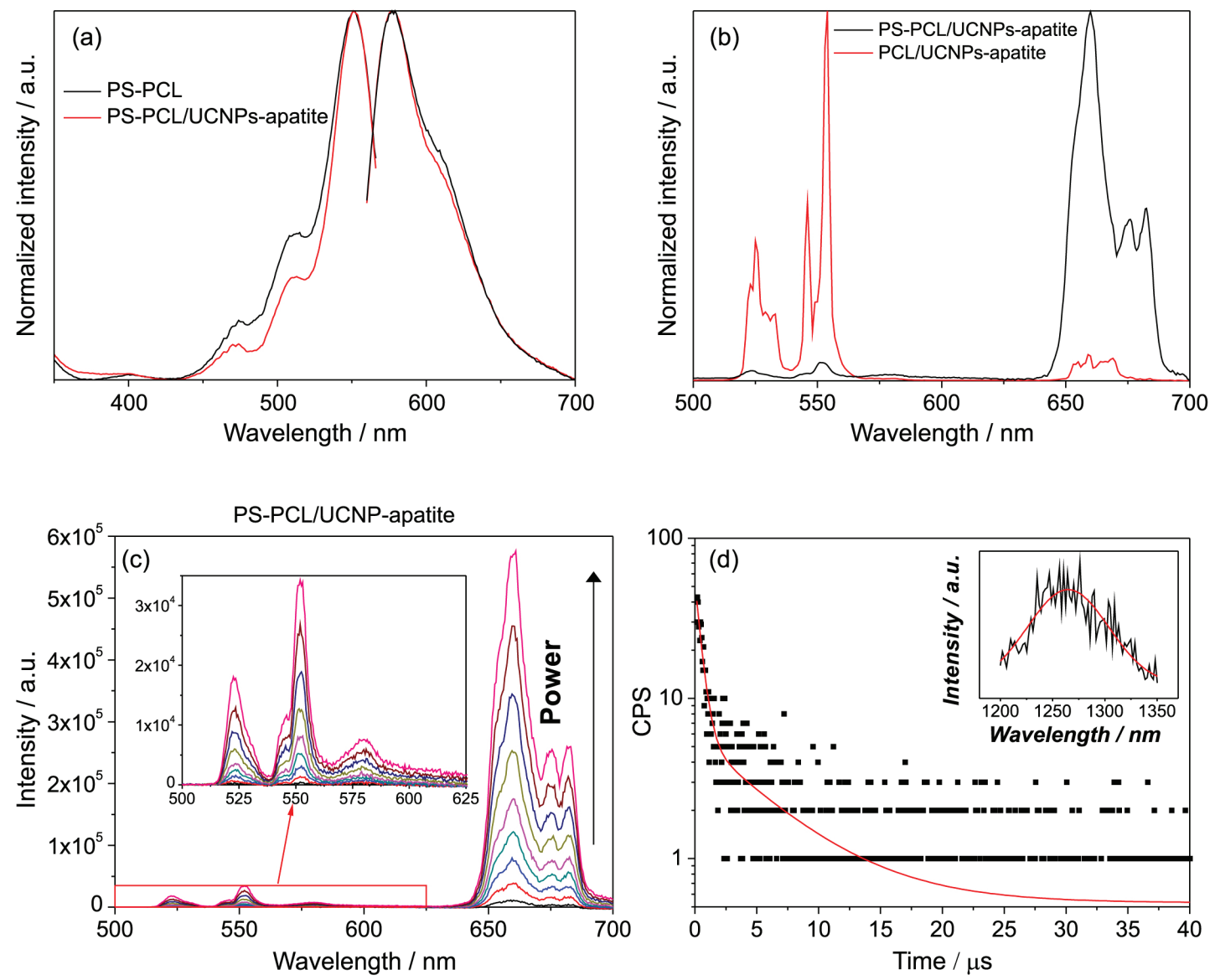

Figure 5. (a) Photoluminescence excitation $\left(\lambda_{\mathrm{em}} 575 \mathrm{~nm}\right)$ and emission $\left(\lambda_{\mathrm{ex}} 551 \mathrm{~nm}\right)$ spectra obtained for PS-PCL/UCNPs-apatite and PS-PCL. (b) Upconversion emission spectra of PCL/UCNPs-apatite and PS-PCL/UCNPs-apatite composites. (c) Up-conversion emission spectra obtained using $980 \mathrm{~nm}$ laser pumping at different powers for PS-PCL/UCNPs-apatite composite. The inset shows the amplified spectra in the range from 500 to $625 \mathrm{~nm}$. (d) Singlet oxygen decay curve and exponential fit for PS-PCL/UCNPs-apatite composite in deuterium oxide $\left(\lambda_{\text {exc }} 980 \mathrm{~nm}\right.$ and $\left.\lambda_{\text {em }} 1270 \mathrm{~nm}\right)$.

relation to $\mathrm{NC}(p>0.05)$. The statistical analysis of paired samples indicated no significant difference among all the eluate dilutions $(p>0.05)$.

The clonogenic assay resulted in the survival fraction (Figure 6b), which showed significant difference $(p<0.05)$ between the NC and PC. The tested materials and their respective dilutions were not cytotoxic in relation to NC $(p>0.05)$. Moreover, it may be noted that the purer and less diluted PCL did not compromise the cell proliferation capacity (PCL $100 \%$ or $75 \%$ ). At the $50 \%$ and $25 \%$ of PCL dilutions, there was a reduction of 9 and $19 \%$, respectively. The PCL/UCNPs-apatite composite tested at different dilutions decreased the proliferative capacity of the cells in $9,19,25.8,28.2,25.5,29.1 \%$, respectively; though it did not present significant difference in relation to NC.

Considering all the results of cytotoxicity, the PCL/UCNPs-apatite eluates did not demonstrate cytotoxicity to CHO-K1 cells at any of the tested concentrations (XTT) and did not significantly impaired the cells proliferative capacity (clonogenic survival).

The results of the cytokinesis-blocked micronucleus
(CBMN) assay can be seen in the Table 2. The evaluation of DNA damage at the chromosome level can be made by CBMN assay, which enables the study of an important part of genetic toxicology because the mutation of the chromosomal is related to carcinogenesis. The CBMN assay is one of the preferred method for mutation evaluation because by it both chromosome loss and chromosome breakage is measured reliably. ${ }^{64} \mathrm{NDI}$ is a marker of cell proliferation in cultures, in which it is considered a measure of general cytotoxicity. There was a statistically significant difference of the NDI between the NC and the PC $(p<0.0001$, Tukey's test), as well between the NC and the PCL/UCNPs-apatite eluate at 100\% concentration $(p<0.05$, Dunnett's test). The cell division process was uniform in the other treatments in relation to the NC. It is hypothesized that cells under the effect of mutagenic agents undergo DNA damage, failing to survive the cycle of cell division and thereby undergo a process of necrosis or apoptosis before the end of first division. ${ }^{65}$ This may be the reason for the significant lower NDIs of the PC and the PCL/UCNPs-apatite eluate in the $100 \%$ concentration 
(a)

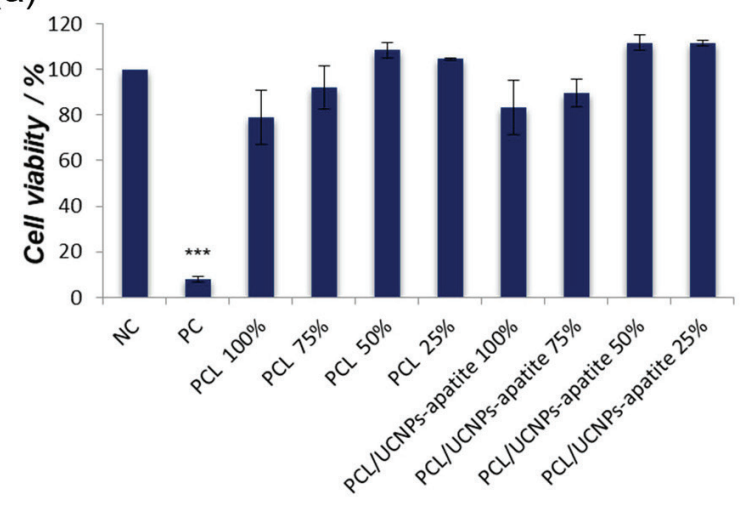

(c)

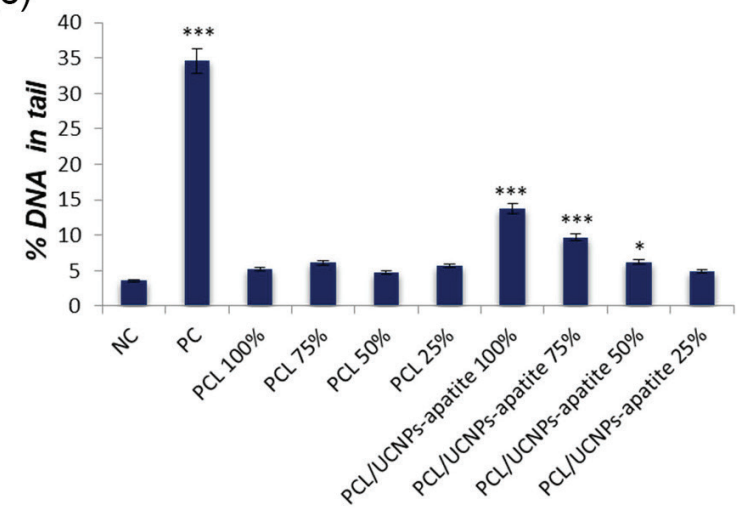

(b)

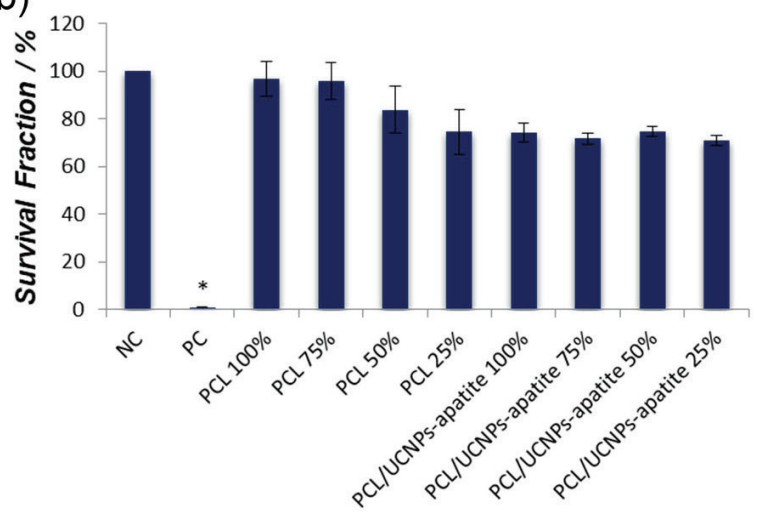

(d)

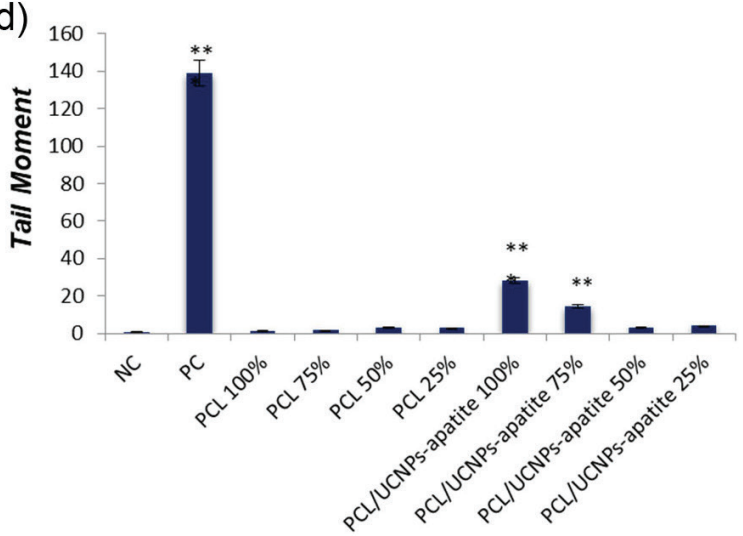

Figure 6. (a) XTT test. Columns: the mean value of the cellular viability (\%); bars: standard error. $* * * p<0.0001$, Dunnett's test. (b) Clonogenic survival assay. Columns: the mean value of the survival fraction (\%); bars: standard error. ${ }^{*} p<0.05$, Kruskal-Wallis test followed by the Dunn's test. (c) Comet assay. Columns: the mean value of $\%$ DNA in tail; bars: standard error. ${ }^{* * *} p<0.0001 ; * p<0.05$, Dunnett's test. (d) Comet test. Columns: the mean value of tail moment; bars: standard error. ${ }^{* * *} p<0.0001 ; * * p<0.05$, Dunnett's test.

Table 2. Nuclear division index (NDI), frequency of micronucleus binucleated cells (MNBC) and micronucleus (MN). Frequency obtained from each treatment and controls

\begin{tabular}{lccc}
\hline Group & NDI & MNBC & MN \\
\hline NC & $1.94 \pm 0.0215$ & $30.0 \pm 2.3$ & $32.7 \pm 2.3$ \\
PC & $1.76 \pm 0.019^{\mathrm{a}}$ & $96.3 \pm 5.4^{\mathrm{b}}$ & $143.7 \pm 8.4^{\mathrm{b}}$ \\
PCL 100 & $1.93 \pm 0.005$ & $25.00 \pm 0.89$ & $28.00 \pm 0.89$ \\
PCL 75 & $1.93 \pm 0.005$ & $29.3 \pm 1.4$ & $31.0 \pm 1.6$ \\
PCL 50 & $1.93 \pm 0.007$ & $31.7 \pm 1.4$ & $33.7 \pm 1.9$ \\
PCL 25 & $1.92 \pm 0.004$ & $37.7 \pm 1.4$ & $40.3 \pm 1.9$ \\
PCL/UCNPs-apatite 100 & $1.89 \pm 0.014^{\mathrm{c}}$ & $103.0 \pm 3.2^{\mathrm{b}}$ & $130.7 \pm 4.5^{\mathrm{b}}$ \\
PCL/UCNPs-apatite 75 & $1.94 \pm 0.007$ & $48.3 \pm 1.4^{\mathrm{b}}$ & $53.3 \pm 2.2^{\mathrm{b}}$ \\
PCL/UCNPs-apatite 50 & $1.90 \pm 0.007$ & $42.3 \pm 2.3^{\mathrm{c}}$ & $43.3 \pm 1.4$ \\
PCL/UCNPs-apatite 25 & $1.93 \pm 0.007$ & $29.0 \pm 1.8$ & $32.3 \pm 2.3$ \\
\hline
\end{tabular}

NDI: nuclear division index; MNBC: frequency of micronucleus binucleated cells; MN: micronucleus; NC: negative control; PC: positive control; PCL: polycaprolactone; PCL/UCNPs-apatite: polycaprolactone/UCNPs apatite composite material. ${ }^{\mathrm{a}} p<0.0001$, Tukey's test; ${ }^{\mathrm{b}} p<0.0001 ;{ }^{\mathrm{c}} p<0.05$ difference in relation to NC, Dunnett's test.

in comparison to the NC. There may also be an induction of mitotic delay which, by not permitting the repair of genotoxic lesions, will modify the number of cells entering mitosis by modifying the ratio of mono, bi-, tri- and tetranucleated cells. Thus, there is a lower NDI because of the smaller number of dividing cells. Furthermore, there is a hypothesis of a clastogenic effect of mutagenic agents with aneugenic action, inducing some degree of cell cycle blockade. Therefore, more cells will not divide, and NDI will remain low. ${ }^{65}$ 
According to the results related to the amount of binucleated cells with micronucleus (MNBC) and the micronucleus frequency $(\mathrm{MN})$, as expected, there was significant difference between the NC and the PC, but none of the eluates concentrations of the PCL sample showed mutagenicity, since there was no statistically significant difference to the NC ( $p>0.05$, Tukey's and Dunnett's tests).

In the evaluation of MNBC frequency, there were significant difference in relation to NC the PCL/UCNPsapatite at concentrations of $100 \%, 75 \%(p<0.0001$; Tukey's test) and at the concentration of 50\% $(p<0.01$; Tukey's test), indicating mutagenicity associated with the presence of rare-earth elements (UCNPs-apatite) with increasing concentration. Regarding the MN frequency, as expected, significantly higher number of micronucleus was observed in the PC in comparison with the $\mathrm{NC}$, as well as, the eluates prepared from the PCL/UCNPs-apatite at $100 \%$ and $75 \%$ concentrations $(p<0.0001$, Tukey's and Dunnett's tests).

Considering both the MNBC and MN frequency results, only the lowest concentration (25\%) of the PCL/UCNPsapatite eluate and the eluates of PCL materials were not mutagenic. There was a mutagenic potential of the highest concentrations of the eluates of the PCL/UCNPs-apatite, expressing a direct relation of mutagenicity with the increase of the eluate concentration.

PCL associated to poly(ethylene glycol) (PEG) was synthesized and the obtained PCEC nanomaterials also presented no genotoxic and mutagenic effects evaluated in Ames test, in the in vitro chromosomal aberration assay, and in the in vivo micronucleus assay. ${ }^{66}$

The DNA damage can be evaluated in the alkaline single-cell gel electrophoresis or comet assay, which is a highly used method in wide range of fields, from molecular epidemiology to genetic toxicology ${ }^{67}$ Comet assay enables the evaluation of both single and doublestrand fragmentations in DNA, and the alkali labile sites expressed as frank strand breaks in the DNA. ${ }^{44,68}$

In relation to the genotoxic potential (comet assay), analyzing the DNA percentage in the tail (Figure 6c), it can be observed that the PCL associated with PCL/UCNPsapatite at concentrations of $100 \%, 75 \%$ and $50 \%$ were genotoxic. PCL sample at all concentrations tested did not present a statistically significant difference in relation to the NC ( $p>0.05$; Dunnett's test).

According to the tail moment results (Figure 6d), a direct relationship of genotoxicity was also observed with the increase of the eluate concentration in the PCL/UCNPsapatite material, while only the highest concentrations (100 and 75\%) were genotoxic. The other concentrations of PCL/UCNPs-apatite eluates and the pure PCL eluates did not present genotoxicity ( $p>0.05$; Dunnett's test).

The tail moment means the amount and distance of the DNA fragments migrated during electrophoresis. Therefore, at the lowest concentrations of PCL/UCNPsapatite, and at all concentrations of the PCL samples there were no statistically significant difference of the tail moment with the NC. However, it is evidenced that the presence of higher concentration of UCNPs-apatite in the PCL was able to induce genotoxicity in the material.

When the two tests performed to investigate cytotoxicity (XTT and clonogenic survival) were analyzed together, the dilutions of PCL polymer and PCL/UCNPs-apatite did not show any cytotoxic, inducing good cell viability index (XTT) and did not significantly impair the cells proliferative capacity (clonogenic survival). Catauro et al. ${ }^{69}$ evaluated the cytotoxicity of a hybrid material consisting of PCL associated with the titanium oxide by the MTT test and the trypan blue exclusion test. The authors verified that the material studied had good biological properties and could be considered a bioactive material with potential for dental and orthopedic applications. UCNPs $\mathrm{Y}_{2} \mathrm{O}_{3} / \mathrm{Yb}^{3+}$, $\mathrm{Er}^{3+}$ functionalized with folic acid (UCNPs- $\mathrm{NH}_{2}-\mathrm{FA}$ ) was prepared and the cytotoxicity of different concentrations was evaluated with MTT assay in three cancer cell lines (HeLa, MDA-MB-231 and MCF-7), and genotoxicity was measured with comet assay. ${ }^{68}$ The authors verified that some concentrations of bare UCNPs were cytotoxic for cells, however, after been functionalized, UCNPs were non-cytotoxic. Both bare and functionalized UCNPs were non-genotoxic for any concentration. The amount of PCL appeared to affect cell proliferation, wherein an increase in the amount of PCL was observed to result in increased cell viability. Similar result was observed in the clonogenic survival assay of the present study in PCL polymer at 100 and $75 \%$ concentrations identified no significant impairment of cell proliferative capacity. The evaluation of the cytotoxicity of PCL at 100 and $75 \%$ concentrations and the PCL/UCNPs-apatite by the XTT test to identify a reduction in cell viability, these materials were classified as non-cytotoxic $(p>0.05)$. Hilderbrand et al. ${ }^{70}$ have concluded from preliminary studies on $\mathrm{Y}_{2} \mathrm{O}_{3}$-based UCNPs that these materials had low toxicity. The rareearth elements $\mathrm{Yb}^{3+}: \mathrm{Er}^{3+}$ doped in the $\mathrm{Y}_{2} \mathrm{O}_{3}$ host matrix are an emerging alternative for use in optical imaging demonstrating low cytotoxicity. Therefore, the results of our study are in agreement with that of Hilderbrand et al. ${ }^{70}$ showing that the presence of rare earth did not expressively interfere in the cytotoxic character of the material. In other words, despite the reduction of cell viability in the test of the XTT at $100 \%$ and $75 \%$ PCL/UCNPs-apatite dilutions, 
this difference was not statistically significant in relation to $\mathrm{NC}(p>0.05)$. Moreover, there was no significant reduction in the proliferative capacity of the eluate of materials in the clonogenic survival test.

\section{Conclusions}

A luminescent material based on apatite combined with UCNPs was prepared. To this material, a polymer (PCL) was added, and a composite PCL/UCNPs-apatite was obtained by an extrusion process. 3D-printed scaffolds using PCL/UCNPs-apatite filaments were easily manufactured by fused filament fabrication (FFF) technology. PCL/UCNPs-apatite filaments presented a thermal and rheological behavior similar to the PCL filament; moreover, PCL/UCNPs-apatite composite showed to be easy processing and low production cost compared with other resorbable polymers for medical applications. The addition of the inorganic component ensured a mechanical strength gain of approximately 3 times. Furthermore, the PCL/UCNPs-apatite composite presented upconversion property and the 3D-printed scaffold did not interfere on its optical property, demonstrating the possibility to use PCL/UCNPs-apatite scaffolds in PDT process under NIR excitation. Therefore, the composite showed to be a multifunctional-alloplastic material for different biomedical applications.

Considering the cytotoxicity assays (XTT and clonogenic survival) results after the CHO-K1 cells treatment with the PCL polymer or PCL/UCNPs-apatite, we demonstrated that this composite showed positive promise for utilization in the therapy-stimulated bone repair/regeneration and photodynamic therapy. However, according to the comet assay and the micronucleus test to the CHO-K1 cells, we found that the PCL/UCNPs-apatite were genotoxicity and mutagenic at higher concentrations of rare-earth elements. Additional studies could be carried out to confirm these results, but for the present moment it may be suggested the use of these materials at low concentrations, ensuring the safety of these biomaterials for tissue engineering and medicine regenerative applications.

\section{Supplementary Information}

Supplementary information (morphological, structural and thermal characterization: photographs of composite material (PCL/UCNPs-apatite); SEM images of UCNPs, UCNPs-apatite and PCL/UCNPs-apatite; XRD of UCNPs and UCNPs-apatite; and DSC curves of PCL and PCL/UCNPs-apatite) is available free of charge at http://jbcs.sbq.org.br as a PDF file.

\section{Acknowledgments}

This study was supported by the Brazilian agencies FAPESP, CAPES (Finance code 001 and Nanobiotec 13) and CNPq.

\section{Author Contributions}

K. N., S. S. and L. M. C. performed the experimental work of synthesis and characterization of materials, wrote and reviewed the manuscript. A. T. extruded the composite to obtain the standardized filaments. P. I. N. and J. V. L. S. produced the 3D printed composite scaffolds. C. A. G. B. and A. A. L. conducted the mechanical analysis. F. C., R. M. S.-C. and T. S. O. C. performed the cytotoxicity, genotoxicity and mutagenicity assays, analyzed the results and wrote part of this manuscript. M. S. B., L. H. C., S. J. L. R. headed the investigation and conceived the experimental plan.

\section{References}

1. Auzel, F.; Chem. Rev. 2004, 104, 139; Zhang, F. In Photon Upconversion Nanomaterials; Springer-Verlag: Berlin, Germany, 2015.

2. Nie, Q.; Wang, Y.; Jia, L.; Liu, B.; Liu, E.; Hu, X.; Fan, J.; J. Alloys Compd. 2017, 722, 896; Tang, Y.; Li, M.; Gao, Z.; Liu, X.; Gao, X.; Ma, T.; Lu, X.; Li, J.; Food Anal. Methods 2017, 10, 2964.

3. Brites, C. D.; Lima, P. P.; Silva, N. J.; Millán, A.; Amaral, V. S.; Palacio, F.; Carlos, L. D.; Nanoscale 2012, 4, 4799; Nigoghossian, K.; Messaddeq, Y.; Boudreau, D.; Ribeiro, S. J. L.; ACS Omega 2017, 2, 2065.

4. Ma, X.; Ni, X.; J. Mater. Sci.: Mater. Electron. 2015, 26, 1129.

5. Balaji, R.; Kumar, S.; Reddy, K. L.; Sharma, V.; Bhattacharyya, K.; Krishnan, V.; J. Alloys Compd. 2017, 724, 481.

6. Zhou, L.; Zheng, X.; Gu, Z.; Yin, W.; Zhang, X.; Ruan, L.; Yang, Y.; Hu, Z.; Zhao, Y.; Biomaterials 2014, 35, 7666; Alkahtani, M. H.; Alghannam, F. S.; Sanchez, C.; Gomes, C. L.; Liang, H.; Hemmer, P. R.; Nanotechnology 2016, 27, 485501; Hu, Y.; Wu, B.; Jin, Q.; Wang, X.; Li, Y.; Sun, Y.; Huo, J.; Zhao, X.; Talanta 2016, 152, 504; Chen, Z.; Zheng, W.; Huang, P.; Tu, D.; Zhou, S.; Huang, M.; Chen, X.; Nanoscale 2015, 7, 4274; Yang, B.; Zhang, Y.; Chen, B.; He, M.; Yin, X.; Wang, H.; Li, X.; Hu, B.; Biosens. Bioelectron. 2017, 96, 77.

7. Zohar, O.; Ikeda, M.; Shinagawa, H.; Inoue, H.; Nakamura, H.; Elbaum, D.; Alkon, D. L.; Yoshioka, T.; Biophys. J. 1998, 74, 82.

8. He, M.; Li, Z.; Ge, Y.; Liu, Z.; Anal. Chem. 2016, 88, 1530.

9. Jin, B.; Wang, S.; Lin, M.; Jin, Y.; Zhang, S.; Cui, X.; Gong, Y.; Li, A.; Xu, F.; Lu, T. J.; Biosens Bioelectron. 2017, 90, 525; 
Guan, Y.; Qu, S.; Li, B.; Zhang, L.; Ma, H.; Zhang, L.; Biosens. Bioelectron. 2016, 77, 124.

10. You, M.; Lin, M.; Gong, Y.; Wang, S.; Li, A.; Ji, L.; Zhao, H.; Ling, K.; Wen, T.; Huang, Y.; Gao, D.; Ma, Q.; Wang, T.; Ma, A.; Li, X.; Xu, F.; ACS Nano 2017, 11, 6261.

11. Bagheri, A.; Arandiyan, H.; Boyer, C.; Lim, M.; Adv. Sci. 2016, 3, 1500437; Li, Y.; Chen, X.; Liu, H.; Mou, X.; Ren, Z.; Ahmad, Z.; Li, X.; Han, G.; Chem. Eng. J. 2017, 330, 166.

12. Idris, N. M.; Jayakumar, M. K. G.; Bansal, A.; Zhang, Y.; Chem. Soc. Rev. 2015, 44, 1449; Nigoghossian, K.; Ouellet, S.; Plain, J.; Messaddeq, Y.; Boudreau, D.; Ribeiro, S. J. L.; J. Mater. Chem. B 2017, 5, 7109.

13. Qiao, H.; Cui, Z.; Yang, S.; Ji, D.; Wang, Y.; Yang, Y.; Han, X.; Fan, Q.; Qin, A.; Wang, T.; He, X.-P.; Bu, W.; Tang, T.; ACS Nano 2017, 11, 7259; Huang, Y.; Xiao, Q.; Hu, H.; Zhang, K.; Feng, Y.; Li, F.; Wang, J.; Ding, X.; Jiang, J.; Li, Y.; Shi, L.; Shi, L.; Small 2016, 12, 4200.

14. Li, Z.; Zhang, Y.; Jiang, S.; Adv. Mater. 2008, 20, 4765; Wang, F.; Deng, R.; Liu, X.; Nat. Protoc. 2014, 9, 1634.

15. Idris, N. M.; Gnanasammandhan, M. K.; Zhang, J.; Ho, P. C.; Mahendran, R.; Zhang, Y.; Nat. Med. 2012, 18, 1580; Lu, S.; Tu, D.; Hu, P.; Xu, J.; Li, R.; Wang, M.; Chen, Z.; Huang, M.; Chen, X.; Angew. Chem., Int. Ed. 2015, 54, 7915; Liang, L.; Care, A.; Zhang, R.; Lu, Y.; Packer, N. H.; Sunna, A.; Qian, Y.; Zvyagin, A. V.; ACS Appl. Mater. Interfaces 2016, 8, 11945.

16. Calixto, G. M. F.; Bernegossi, J.; de Freitas, L. M.; Fontana, C. R.; Chorilli, M.; Molecules 2016, 21, 342.

17. Hemmer, E.; Benayas, A.; Légaré, F.; Vetrone, F.; Nanoscale Horiz. 2016, 1, 168.

18. Deda, D. K.; Araki, K.; J. Braz. Chem. Soc. 2015, 26, 2448.

19. Xu, F.; Ding, L.; Tao, W.; Yang, X. Z.; Qian, H. S.; Yao, R. S.; Mater. Lett. 2016, 167, 205.

20. Dziadek, M.; Stodolak-Zych, E.; Cholewa-Kowalska, K.; Mater. Sci. Eng., C 2017, 71, 1175.

21. Mano, J. F.; Silva, G. A.; Azevedo, H. S.; Malafaya, P. B.; Sousa, R. A.; Silva, S. S.; Boesel, L. F.; Oliveira, J. M.; Santos, T. C.; Marques, A. P.; Neves, N. M.; Reis, R. L.; J. R. Soc., Interface 2007, 4, 999.

22. Utela, B.; Storti, D.; Anderson, R.; Ganter, M.; J. Manuf. Mater. Process. 2008, 10, 96; Pereira, T. F.; Oliveira, M. F.; Maia, I. A.; Silva, J. V.; Costa, M. F.; Thiré, R. M.; Macromol. Symp. 2012, 319, 64.

23. Park, S.; Kim, G.; Jeon, Y. C.; Koh, Y.; Kim, W.; J. Mater. Sci.: Mater. Med. 2009, 20, 229; Mouriño, V.; Boccaccini, A. R.; J. R. Soc., Interface 2009, 7, 209.

24. Mazzoli, A.; Med. Biol. Eng. Comput. 2013, 51, 245; Bose, S.; Vahabzadeh, S.; Bandyopadhyay, A.; Mater. Today 2013, 16 , 496.

25. Mei, N.; Chen, G.; Zhou, P.; Chen, X.; Shao, Z. Z.; Pan, L. F.; Wu, C. G.; J. Biomater. Appl. 2005, 19, 323; Hoque, M. E.;
San, W. Y.; Wei, F.; Li, S.; Huang, M. H.; Vert, M.; Hutmacher, D. W.; Tissue Eng., Part A 2009, 15, 3013; Woodruff, M. A.; Hutmacher, D. W.; Prog. Polym. Sci. 2010, 35, 1217.

26. Burg, K. J. L.; Inskeep, B.; Burg, T. C. In Principles of Tissue Engineering, $4^{\text {th }}$ ed.; Lanza, R.; Langer, R.; Vacanti, J. P., eds.; Academic Press: San Diego, USA, 2011, ch. 36.

27. Gomes, S.; Rodrigues, G.; Martins, G.; Henriques, C.; Silva, J. C.; Int. J. Biol. Macromol. 2017, 102, 1174; Vocetkova, K.; Buzgo, M.; Sovkova, V.; Bezdekova, D.; Kneppo, P.; Amler, E.; Cell Proliferation 2016, 49, 568.

28. Barbarisi, M.; Marino, G.; Armenia, E.; Vincenzo, Q.; Rosso, F.; Porcelli, M.; Barbarisi, A.; J. Biomed. Mater. Res., Part A 2015, 103, 1755; Valmikinathan, C. M.; Defroda, S.; Yu, X.; Biomacromolecules 2009, 10, 1084.

29. Maghdouri-White, Y.; Bowlin, G. L.; Lemmon, C. A.; Dréau, D.; Mater. Sci. Eng., C 2016, 59, 1168.

30. Gómez-Lizárraga, K. K.; Flores-Morales, C.; del Prado-Audelo, M. L.; Álvarez-Pérez, M. A.; Piña-Barba, M. C.; Escobedo, C.; Mater. Sci. Eng., C 2017, 79, 326; Jensen, J.; Rölfing, J. H. D.; Le, D. Q. S.; Kristiansen, A. A.; Nygaard, J. V.; Hokland, L. B.; Bendtsen, M.; Kassem, M.; Lysdahl, H.; Bünger, C. E.; J. Biomed. Mater. Res. A 2014, 102, 2993.

31. Park, S. A.; Lee, S. H.; Kim, W. D.; Bioprocess Biosyst. Eng. 2011, 34, 505.

32. Gmati, N.; Boughzala, K.; Salem, E. B.; Chabene, A.; Fattah, N.; Bouzouita, K.; C. R. Chim. 2014, 17, 920.

33. Heydari, Z.; Mohebbi-Kalhori, D.; Afarani, M. S.; Mater. Sci. Eng., C 2017, 81, 127.

34. Shim, J. H.; Won, J. Y.; Park, J. H.; Bae, J. H.; Ahn, G.; Kim, C. H.; Lim, D. H.; Cho, D. W.; Yun, W. S.; Bae, E. B.; Jeong, C. M.; Huh, J. B.; Int. J. Mol. Sci. 2017, 18, 899; Kim, M. S.; Kim, G. H.; Mater. Lett. 2014, 120, 246.

35. Akkouch, A.; Zhang, Z.; Rouabhia, M.; J. Biomed. Mater. Res., Part A 2011, 96A, 693.

36. Filipovic, N.; Stevanovic, M.; Nunic, J.; Cundric, S.; Filipic, M.; Uskokovic, D.; Colloids Surf., B 2014, 117, 414.

37. Wang, W.; Deng, L.; Huang, P.; Xu, S.; Li, X.; Lv, N.; Wang, L.; Hu, R.; Zhang, J.; Dong, A.; J. Biomed. Mater. Res., Part A 2014, $102,17$.

38. Ramasamy, P.; Chandra, P.; Rhee, S. W.; Kim, J.; Nanoscale 2013, 5, 8711.

39. Roh, H. S.; Myung, S. W.; Jung, S. C.; Kim, B. H.; J. Nanosci. Nanotechnol. 2015, 15, 5585; Gonçalves, E. M.; Oliveira, F. J.; Silva, R. F.; Neto, M. A.; Fernandes, M. H.; Amaral, M.; Vallet-Regí, M.; Vila, M.; J. Biomed. Mater. Res., Part B 2016, $104,1210$.

40. Nigoghossian, K.; Peres, M. F. S.; Primo, F. L.; Tedesco, A. C.; Pecoraro, E.; Messaddeq, Y.; Ribeiro, S. J. L.; Colloids Interface Sci. Commun. 2014, $2,6$.

41. Systèmes, D.; 3D CAD Design Software SolidWorks; Dassault Systèmes SolidWorks Corp., France, 2012. 
42. Malone, E.; Lipson, H.; Fab@Home software; Cornell University, USA, 2007.

43. ISO 10993-12:2012: Biological Evaluation of Medical DevicesPart 12: Sample Preparation and Reference Materials, ISO: Geneva, Switzerland, 2012.

44. Singh, N. P. V.; Mccoy, M. T.; Tice, R. R.; Schneider, E. L.; Exp. Cell Res. 1988, 175, 184.

45. Fenech, M.; Mutat Res. 1997, 392, 11.

46. GraphPad Prism, version 5.01; GraphPad Software Inc., San Diego, USA, 2007.

47. Software F980 version 1.2.2; Edinburgh Instruments Ltd., United Kingdom.

48. Cardoso, G. B. C.; Ramos, S. L. F.; Rodas, A. C. D.; Higa, O. Z.; Zavaglia, C. A. C.; Arruda, A. C. F.; J. Mater. Sci. 2010, 45, 4990.

49. Li, Y. S.; Harn, H. J.; Hsieh, D. K.; Wen, T. C.; Subeq, Y. M.; Sun, L. Y.; Lin, S. Z.; Chiou, T. W.; Cell Transplant. 2013, 22, 685.

50. Wang, X.; Yan, Y.; Zhang, R.; Trends Biotechnol. 2007, 25, 505.

51. Silva, V. V.; Lameiras, F. S.; Mater. Charact. 2000, 45, 51; Rajabzadeh, G.; Salehi, S.; Nemati, A.; Tavakoli, R.; Hashjin, M. S.; J. Mech. Behav. Biomed. Mater. 2014, 29, 317.

52. Cimino, N.; Artuso, F.; Decker, F.; Orel, B.; Vuk, A. Š.; Zanoni, R.; Solid State Ionics 2003, 165, 89.

53. Beatrice, C. A. G.; Branciforti, M. C.; Alves, R. M. V.; Bretas, R. E. S.; J. Appl. Polym. Sci. 2010, 116, 3581.

54. Canevarolo Jr., S. V.; Técnicas de Caracterização de Polímeros; Artliber: São Paulo, Brazil, 2003.

55. Maia, T. H. S.; Larocca, N. M.; Beatrice, C. A. G.; Menezes, A. J.; Siqueira, G. F.; Pessan, L. A.; Dufresne, A.; França, M. P.; Lucas, A. A.; Carbohydr. Polym. 2017, 173, 50.

56. Campos, A. D.; Teodoro, K. B.; Marconcini, J. M.; Mattoso, L. H.; Martins-Franchetti, S. M.; Polímeros 2011, 21, 217; Eshraghi, S.; Das, S.; Acta Biomater. 2012, 8, 3138.

57. Fritsch, A.; Dormieux, L.; Hellmich, C.; Sanahuja, J.; J. Biomed. Mater. Res., Part A 2009, 88, 149.

58. Mialon, G.; Türkcan, S.; Dantelle, G.; Collins, D. P.; Hadjipanayi, M.; Taylor, R. A.; Gacoin, T.; Alexandrou, A.; Boilot, J. P.; J. Phys. Chem. C 2010, 114, 22449.

59. Bai, X.; Song, H.; Pan, G.; Lei, Y.; Wang, T.; Ren, X.; Lu, S.; Dong, B.; Dai, Q.; Fan, L.; J. Phys. Chem. C 2007, 111, 13611.
60. Costa, A. C. B. P.; de Campos Rasteiro, V. M.; Pereira, C. A.; da Silva Hashimoto, E. S. H.; Beltrame, M.; Junqueira, J. C.; Jorge, A. O. C.; Arch. Oral Biol. 2011, 56, 1299.

61. Wood, S.; Metcalf, D.; Devine, D.; Robinson, C.; J. Antimicrob. Chemother. 2006, 57, 680, DOI: 10.1093/jac/dk1021; Borba, A. S. M.; Pereira, S. M. S.; Borba, M. C. M.; Paschoal, M. A. B.; Tavarez, R. R. J.; Rizzi, C. C.; Ferreira, M. C.; Maia Filho, E. M.; Photodiagn. Photodyn. Ther. 2017, 19, 348; Costa, A. C. B. P.; Rasteiro, V. M. C.; Pereira, C. A.; Rossoni, R. D.; Junqueira, J. C.; Jorge, A. O. C.; Mycoses 2012, 55, 56; de Carvalho Goulart, R.; Thedei Jr., G.; Souza, S. L.; Tedesco, A. C.; Ciancaglini, P.; Photomed. Laser Surg. 2010, 28, S-85.

62. Nonell, S.; Flors, C.; Singlet Oxygen, vol. 2, The Royal Society of Chemistry: Cambridge, UK, 2016.

63. Torra, J.; Burgos-Caminal, A.; Endres, S.; Wingen, M.; Drepper, T.; Gensch, T.; Ruiz-González, R.; Nonell, S.; Photochem. Photobiol. Sci. 2015, 14, 280; Firey, P. A.; Rodgers, M. A. J.; Photochem. Photobiol. 1987, 45, 535; Martire, D. O.; Jux, N.; Aramendia, P. F.; Martin Negri, R.; Lex, J.; Braslavsky, S. E.; Schaffner, K.; Vogel, E.; J. Am. Chem. Soc. 1992, 114, 9969; Rubio, N.; Sánchez-García, D.; Jiménez-Banzo, A.; Rey, Ó.; Borrell, J. I.; Teixidó, J.; Nonell, S.; J. Phys. Chem. A 2006, 110,3480 .

64. Fenech, M.; Mutat. Res. 2000, 455, 81.

65. Ionescu, M. E.; Ciocirlan, M.; Becheanu, G.; Nicolaie, T.; Ditescu, C.; Teiusanu, A. G.; Gologan, S. I.; Arbanas, T.; Diculescu, M. M.; Maedica 2011, 6, 173.

66. Huang, Y.; Hong, G.; Maling, G.; Huaxia, Y.; Yunke, L.; Yuan, G.; Feng, P.; Zhiyong, Q.; Xiaobo, C.; Yinglan, Z.; Mutat. Res. 2010, 696, 101.

67. Liao, W.; McNutt, M. A.; Zhu, W.-G.; Methods 2009, 48, 46.

68. Chávez-García, D.; Juarez-Moreno, K.; Campos, C. H.; Tejeda, E. M.; Alderete, J. B.; Hirata, G. A.; J. Mater. Sci. 2018, 53, 6665.

69. Catauro, M.; Bollino, F.; Papale, F.; Marciano, S.; Pacifico. S.; Mater. Sci. Eng., C 2015, 47, 135.

70. Hilderbrand, A. S.; Shao, F.; Salthouse, C.; Mahmood, U.; Weissleder, R.; Chem. Commun. 2009, 28, 4188.

Submitted: May 23, 2019

Published online: September 23, 2019 